\title{
Analytical Performance of an HPLC and CZE Methods for the Analysis and Separation of Perindopril Erbumine and Indapamide
}

\author{
Ion Valentin*, Imre Silvia, Cârje Anca Gabriela, Muntean Daniela Lucia \\ Department of Analytical Chemistry and Drug Analysis, Faculty of Pharmacy, University of Medicine and Pharmacy of Tîrgu Mureș, Romania
}

Introduction: Perindopril, as an angiotensin converting enzyme inhibitor and indapamide, as a thiazide like diuretic, can be administrated together for the treatment of high blood preasure and other cardiovascular diseases. The aim of this study was to develop two simple and reliable separation methods for perindopril and indapamide by high performance liquid chromatography and capillary zone electrophoresis in order to evaluate their behaviour under separation conditions, for simultaneous separation.

Materials and methods: Standard solutions of perindopril erbumine and indapamide in proper solvents were analized. An Agilent 1100 series HPLC system was used for the separation of the two analytes on a C18 stationary phase (Zorbax Stable Bond $3.5 \mu \mathrm{m}$ ), under an isocratic elution. As a comparative method, an Agilent 7100 series capillary electrophoresis system was used for the development of the electrophoretic method.

Results: Both developed methods turned to comply to the separation performance parameters such as resolution and selectivity, with low limits of detection, wide range of liniarity. No statistical difference concerning precision of the qualitative parameters was observed. Time analysis less than 5 minutes both for chromatographic and electrophoretic separations proved to generate cost and time effective analysis methods.

Conclusions: Two analytical methods, HPLC and CZE respectively, for the separation of perindoprile erbumine and indapamide have been successfully developed, both recording satisfactory analytical parameters.

Keywords: Perindopril, Indapamide, HPLC, CZE, Separation

Received: 15 June / Accepted: 30 July

\section{Introduction}

Cardiovascular diseases, including high blood pressure, are among the most encountered pathologies worldwide and represent a high percentage of death causes, especialy in developed countries. Two important pharmacological classes are used for the treatment of cardiovascular diseases such as angiotensine converting enzyme (ACE) inhibitors and thiazide like diuretics. Perindopril, an ACE inhibitor and indapamide, a thiazide like diuretic, are oftenly encountered together in oral dosage forms, under different concentrations, for their synergistic antihypertensive effect [1].

It is very important to evaluate the posibility of analysis of these two analytes together by simple and reliable analytical methods in order to establish correlations between plasma levels for this two analytes and some biomarkers, aiming finaly patient's pharmacological treatment adjustments [2]. High performance liquid chromaography (HPLC) remains a powerfull technique in quality control of drugs. However, capillay zone electrophoresis (CZE) offers advantages in terms of costs and reliability of chiral separations. The literature lacks in describing CZE simultaneous separation of perindopril and indapamide, and only few HPLC data are available.

* Correspondence to: Valentin lon

E-mail: valentin.ion.mail@gmail.com
The aim of this study was to investigate the separation behaviour of the two analytes by HPLC and CZE and to compare their analytical performances. The separation performance, was evaluated in terms of resolution $(R, R>1.5)$ and selectivity $(\alpha, \alpha>1.2)$. Other relevant analytical parameters were investigated and compared such as limit of detection (LOD); limit of quantification (LOQ); linearity; robustness and qualitative precision.

\section{Materials and methods}

\section{A. Chemicals and reagents}

Reference substances used for this research were perindopril erbumine and indapamide with analytical purity. Acetonitrile (ACN) and methanol (Meck, Germany) were used as solvents for mobile phases or standard solutions preparation. Potassium dihydrogen phosphate (Merck, Germany) and MilliporeQ purified water served for the preparation of the HPLC mobile phases.

\section{B. Instruments}

The HPLC method was developed on an 1100 Series HPLC from Agilent Technologies (USA) equipped with an UV-VIS detector by using a Zorbax $\mathrm{SB}_{18}$ Rapid Resolution $(150 \mathrm{~mm} X 4.5 \mathrm{~mm})$ column with $3.5 \mu \mathrm{m}$ particle size. 
The CZE method was developed on an Agilent 7100 (USA) series platform coupled with a diode array detector. The separation of the two analytes was done inside a $50 \mathrm{~cm}$ silica capillary. Other instruments used for sample preparation consisted in analytical balances (Mettler-Toledo), $\mathrm{pH}$-meter (Mettler-Toledo), shaker, ultrasonic bath (Elma Transsonic).

\section{Chromatographic method development}

An ideal solvent for the preparation of standard stock solutions or other aliquots was chosen to be a mixture of purified MilliporeQ Water and Acetonitrile in a 50:50 ratio, the stability properties of the analytes already being studied [3][4]. Standard solutions of perindopril erbumine and indapamide were prepared by weighing the necessary amount of analyte to obtain standard solution concentrations of $1 \mathrm{mg} / \mathrm{ml}$ separarately and in mixture also. The chromatographic method was developed using a Zorbax $\mathrm{C}_{18}$ Rapid Resolution chromatographic column. Mobile phase composition, column temperature and detection wavelength were varied with the aim of optimising the separation method. Stock solutions have been injected independently and in mixture.

\section{Capillary Electrophoresis method development}

Stock solutions at a concentration level of $1 \mathrm{mg} / \mathrm{ml}$ of perindopril and indapamide were prepared this time in methanol. Migration of the analytes underwent inside a $50 \mathrm{~cm}$ sillica capillary, containing a borate buffer $(50 \mathrm{mM}$, $\mathrm{pH}=9.2$ ). Voltage was set at $25 \mathrm{kV}$, injection tooked place at $30 \mathrm{mbar}$ for 3 seconds, capillary temperature was mantained at 25 degrees celsius. Each injection was preceded by 2 minutes preconditioning step with borate buffer. Detector wavelengths was fixed at four different wavelenghts but the electropherograms were extracted at $210 \mathrm{~nm}$. Stock solutions have been injected independently and in mixture.

\section{E. Analytical methods performance evaluation}

The two methods were evaluated in terms of separation performance (resolution $\mathrm{R}$, selectivity $\alpha$, limit of detection (LOD), limit of quantification (LOQ), linearity/regression analysis, ruggedness, statistical comparison between the two methods concerning the reproducibility of qualitative parameters. The limit of detection was established as beeing the signal in terms of peak height, not less than 3 times noise signal intensity. The limit of quantification was chosen as beeing the lowest concentration where the peak's height is 10 times more intense than the noise signal intensity.

\section{Results and Discussions}

HPLC method optimisation started with the injection of 5 $\mu \mathrm{l}$ stock solution of perindopril erbumine $1 \mathrm{mg} / \mathrm{ml}$ under an isocratic elution (flow $=1 \mathrm{ml} / \mathrm{min}$ ), with a mobile phase consisted in a mixture of potassiun dyhydrogen phosphate buffer $(5 \mathrm{mM}, \mathrm{pH}=2.8)$, acetonitrile and methanol. Detection was set at $215 \mathrm{~nm}$ as a nonspecific wavelength.
Column temperature was set at 25 degrees celsius. Due to the high elution power, methanol was given aside. Further optimisation proceeded with a mixture of potassium dihydrogen phosphate buffer and acetonitrile. Also column temperature was modified upwards with an increment of 2.5 degrees celsius. Finally, satisfactory conditions concerning the shape and time retention of perindopril peak were established at a column temperature of 40 degrees celsius, mobile phase flow $1 \mathrm{ml} / \mathrm{min}$ with a composition of phosphate buffer:ACN=52:48, detection beeing established at $210 \mathrm{~nm}$. In the same conditions a stock solution of indapamide was injected. indapamide showing a different retention time compared to perindopril and also a proper shape of the chromatographic peak. Both analytes were injected together, in mixture, at the same level of concentration $(1 \mathrm{mg} / \mathrm{ml})$.

Optimum chromatographic conditions consisted in an isocratic elution with a mobile phase composed of potassium dihydrogen phosphate buffer $(5 \mathrm{mM}, \mathrm{pH}=2.8)$ and ACN under a ratio of 52:48. Flow was set at $1 \mathrm{ml} / \mathrm{min}$, column temperature mentained at 40 degrees celsius, detection being set at $210 \mathrm{~nm}$. Optimum electrophoretic parameters were chosen as follows: migration in borate $(50 \mathrm{mM}, \mathrm{pH}=9.2)$ buffer, voltage $25 \mathrm{kV}$, capillary temperature-25 degrees celsius, injection at $30 \mathrm{mbar}-3$ seconds, DAD detection set at $210 \mathrm{~nm}$.

\section{A. Separation Performance}

Both HPLC and CZE methods proved to be capable to identify and separate perindopril erbumine and indapamide in less than 5 minutes analysis time (as shown in Figure. 1 and Figure. 2). Separation performance was evaluated in terms of selectivity $\alpha$ and resolution R (Table I) from 6 replicates.

\section{B. Limit of detection and limit of quantification}

The limit of detection and limit of quantification for the two analytes are substantially different both for HPLC and CZE proposed methods. This is due to the low UV absorbtivity of perindoprile because of the relative lack of chromophores in the molecule. Limit of detection and limit of quantification for both methods can be observed in Table II.

As can be seen, LOD for the HPLC method concerning perindopril is one of the lowest concentration level from the present literature [5]. The difference between perindopril LOD and indapamide LOD is due to the low UV absorbtivity of perindopril. This difference can be visible for de CZE method also. Another important difference can be observed concerning the LODs for the two analytes in the two methods, that beeing the fact that the limit of detection for indapamide and perindoprile revealed to be much higher compared to the LODs found for the HPLC method. This experiment confirms once again the disadvantage of the capillary zone electrophorisis with respect to the limit of detection. 


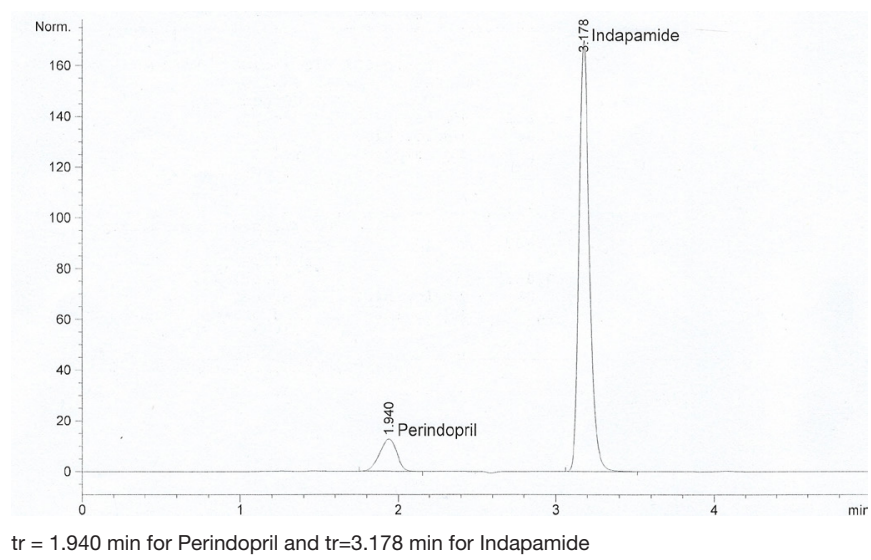

Fig. 1. Typical chromatogram for the separation of perindopril erbumine and indapamide.

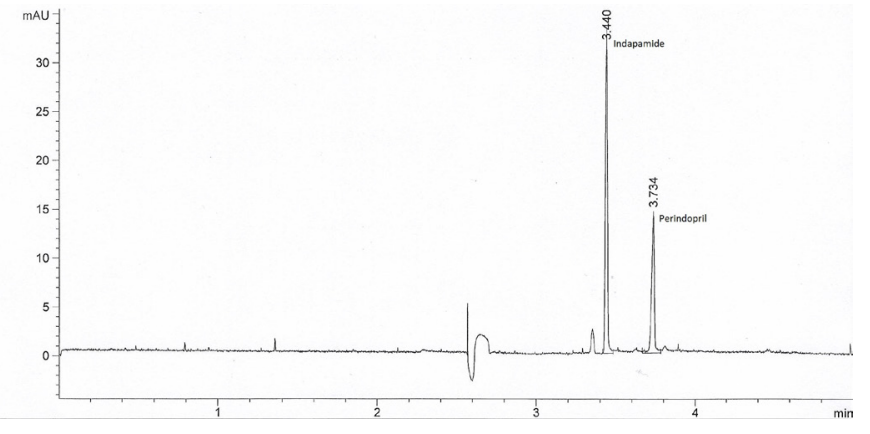

$\mathrm{tm}=3.440 \mathrm{~min}$ for Indapamide and $\mathrm{tm}=3.734 \mathrm{~min}$ for Perindopril

Fig. 2. Typical electropherogram for the separation of perindopril erbumine and indapamide.

Table I. Separation performance for the HPLC and CZE methods respectively ( $N=6$ )

\begin{tabular}{|c|c|c|c|c|c|c|c|}
\hline \multirow{2}{*}{\multicolumn{2}{|c|}{ Analyte }} & \multirow{2}{*}{$\begin{array}{l}\text { Retention time } \\
\text { HPLC Method } \\
\text { (min) }\end{array}$} & \multirow[t]{2}{*}{$\begin{array}{c}\text { Migration Time } \\
\text { CZE Method (min) }\end{array}$} & \multicolumn{2}{|c|}{$\mathrm{R}$} & \multicolumn{2}{|c|}{$\alpha$} \\
\hline & & & & HPLC & CZE & HPLC & CZE \\
\hline \multicolumn{2}{|c|}{ Perindopril } & 1,93 & 3,59 & \multirow{2}{*}{7,78} & \multirow{2}{*}{5,5} & \multirow{2}{*}{6,14} & \multirow{2}{*}{1,10} \\
\hline & & 3,17 & 3,24 & & & & \\
\hline \multirow{2}{*}{ STDV } & Perindopril & 0,0098 & 0,005 & \multirow{2}{*}{0,058} & \multirow{2}{*}{0,099} & \multirow{2}{*}{0,10} & \multirow{2}{*}{0,0214} \\
\hline & Indapamide & 0,0016 & 0,019 & & & & \\
\hline \multirow{2}{*}{ CV (\%) } & Perindopril & 0,51 & 0,14 & \multirow{2}{*}{0,75} & \multirow{2}{*}{1,8} & \multirow{2}{*}{1,74} & \multirow{2}{*}{1,95} \\
\hline & Indapamide & 0,05 & 0,60 & & & & \\
\hline
\end{tabular}

Table II. LOD and LOQ for the proposed HPLC and CZE methods

\begin{tabular}{lcccc}
\hline \multirow{2}{*}{ Analyte } & \multicolumn{2}{c}{$\operatorname{LOD}(\mu \mathrm{g} / \mathrm{ml})$} & \multicolumn{2}{c}{ LOQ $(\mu \mathrm{g} / \mathrm{ml})$} \\
\cline { 2 - 5 } & $\begin{array}{c}\text { HPLC } \\
\text { method }\end{array}$ & $\begin{array}{c}\text { CZE } \\
\text { method }\end{array}$ & $\begin{array}{c}\text { HPLC } \\
\text { method }\end{array}$ & $\begin{array}{c}\text { CZE } \\
\text { method }\end{array}$ \\
\hline Perindopril & 2 & 200 & 4 & 250 \\
\hline Indapamide & 0.4 & 25 & 4 & 50 \\
\hline
\end{tabular}

\section{Linearity and regression analysis}

For the HPLC method, linearity domain was established between 4 and $500 \mu \mathrm{g} / \mathrm{ml}$ both for perindopril and indapamide, respectively, with a total of seven calibration points. Due to much higher LOD and LOQ for the CZE method, linearity domain for indapamide was established between 50 and $400 \mu \mathrm{g} / \mathrm{ml}$ for indapamide and a domain between 250 and $1750 \mu \mathrm{g} / \mathrm{ml}$ for perindopril. Linearity for the CZE method was computed on five calibration points. Regresion analysis for both methods are summarised in the tables III and IV.

HPLC method showed a good correlation between the experimental points and the trendline on a broad liniarity interval $4-500 \mu \mathrm{g} / \mathrm{ml}$, both for perindopril and indapamide. Good results in terms of liniarity were encountered for the CZE method also but on a higher interval of concentrations beacause of the LOQs diferences between the two methods.

\section{Ruggedness}

Robustness was estimated tacking into consideration the temperature variations of the chromatographic column or
Table III. Regression analysis for perindopril and indapamide HPLC method ( $\mathrm{N}=7)$

\begin{tabular}{lccc}
\hline HPLC Perindoprile & Coefficients & HPLC Indapamide & Coefficients \\
\hline Intercept & -0.7006 & Intercept & 423.6073 \\
\hline X Variable 1 & 4.8208 & X Variable 1 & 29.4953 \\
\hline Regression Statistics & & Regression Statistics \\
\hline Multiple R & 0.9999 & Multiple R & 0.9952 \\
\hline R Square & 0.9998 & R Square & 0.9904 \\
\hline Adjusted R Square & 0.9997 & Adjusted R Square & 0.9885 \\
\hline
\end{tabular}

Table IV. Regression analysis for perindopril and indapamide - CZE method $(\mathrm{N}=5)$

\begin{tabular}{lccc}
\hline CZE Perindopril & $\begin{array}{c}\text { Co- } \\
\text { efficients }\end{array}$ & CZE Indapamide & $\begin{array}{c}\text { Coef- } \\
\text { ficients }\end{array}$ \\
\hline Intercept & 2.3508 & Intercept & 3.5092 \\
\hline X Variable 1 & 32.7692 & X Variable 1 & 142.1538 \\
\hline Regression Statistics & & Regression Statistics \\
\hline Multiple R & 0.9967 & Multiple R & 0.9953 \\
\hline R Square & 0.9935 & R Square & 0.9906 \\
\hline Adjusted R Square & 0.9913 & Adjusted R Square & 0.9874 \\
\hline
\end{tabular}

silica capillary. Chromatographic parameters met no alteration for a temperature variation of $+/-2$ degrees celsius around 40 degrees celsius. The electrophoretic parameters proved to be constant between 20 up to 26 degrees Celsius. 
Table V. Comparison between qualitative precision of the two methods $(\mathrm{N}=7, \alpha=0.05$ )

\begin{tabular}{lcccc}
\hline $\begin{array}{l}\text { Perindopril } \\
\text { HPLC tr vs CZE tm }\end{array}$ & Variable 1 & Variable 2 & Indapamide & Variable 2 \\
\hline Mean & 1.9321 & 3.5925 & Mean & 3.2435 \\
\hline Variance & 0.000114143 & $3.02857 \mathrm{E}-05$ & Variance & $3.2381 \mathrm{E}-06$ \\
\hline Observations & 7 & 7 & Observations & 7 \\
\hline $\mathrm{F}$ & 3.7688 & & $\mathrm{~F}$ & 0.000454619 \\
\hline $\mathrm{P}(\mathrm{F}<=f)$ one-tail & 0.065 & & $\mathrm{P}(\mathrm{F}<=$ f) one-tail & 3.0071 \\
\hline $\mathrm{F} \mathrm{Critical} \mathrm{one-tail}$ & 4.2838 & $\mathrm{~F}$ Critical one-tail & $3.49 \mathrm{E}-06$ \\
\hline
\end{tabular}

E. Comparison between precision of the qualitative parameters

The two methods have been statistically assesed by comparing the variances of the retention times ( $t_{\mathrm{r}}$ for HPLC) and migration times ( $t_{m}$ for CZE) of perindopril and indapamide with the help of $\mathrm{F}$ test $(\mathrm{N}=7, \alpha=0.05)$. Thus the precision of this two methods can be analysed concerning qualitative parameters such as retention times and migration times (Table V).

F test revealed that, there is no difference between the variances of the retention times from the HPLC method compared to the variances of the migration times from the CZE method for both analytes, respectively.

\section{Conclusions}

On the base of cost effectiveness and time analysis, it was posible to develop two separation methods for simultaneous determination perindoprile erbumine and indapamide with an analysis time of less than 5 minutes for each method. Both methods comply under the separation performance parameters with a good resolution and selectivity, low LODs and broad liniarity range, respectively. As far as we are aware, the proposed CZE method is the first re- ported for simultaneous determination of perindopril and indapamide, with similar performances as for an HPLC method.

\section{Acknowledgements}

This paper is supported by the Sectoral Operational Programme Human Resources Development (SOP HRD), financed from the European Social Fund and by the Romanian Government under the contract number POSDRU/159/1.5/S/137390/

\section{References}

1. Semenkin AA, Zhenatov AB, Zhivilova LA et al. Comparative evaluation of vascular and metabolic effects of perindopril combination with indapamide-retard or hydrochlorothiazide in hypertensive patients. Artery Res. 2011;5:188.

2. Roux A, Lison D, Junot $C$ et al. Applications of liquid chromatography coupled to mass spectrometry-based metabolomics in clinical chemistry and toxicology: A review. Clin Biochem. 2011;44:119-135.

3. Simonic Z, Roskar R, Gartner A, et al. The use of microcalorimetry and HPLC for the determination of degradation kinetics and thermodynamic parameters of Perindopril Erbumine in aqueous solutions. Int J Pharm. 2008;356:200-255.

4. Buckton G. Applications of isothermal microcalorimetry in the pharmaceutical sciences. Thermocim Acta. 1995;248:117-129.

5. Dawd ER, Shakya AK. HPLC-PDA analysis of ACE-inhibitors, hydrochlorothiazide and indapamide utilizing design of experiments. Arab J Chem. 2014. 